\title{
The California Harmful Algal Bloom Monitoring and Alert Program: A Success Story for Coordinated Ocean Observing
}

By Raphael M. Kudela, Clarissa Anderson, and Henry Ruhl

Phytoplankton, microscopic marine algae, are at the base of the food chain in most freshwater and marine systems and provide many positive benefits, including production of about half the oxygen on the planet and transformation of sunlight and inorganic elements into the organic material and energy that drive productive aquatic ecosystems. A subset of the phytoplankton, referred to as harmful algal bloom (HAB) species, such as the domoicacid-producing Pseudo-nitzschia, are persistent threats to coastal resources, local economies, and human and animal health throughout US waters. HABs will likely intensify in response to anthropogenic climate change, and there is an immediate need for more effective strategies for monitoring and communicating the risks of HABs to human and ecosystem health.

The ocean science community has developed several novel sensors and methods for monitoring and predicting this diversity of $\mathrm{HAB}$ events. These include the Imaging FlowCytobot (IFCB) and various biophysical modeling systems optimized for $\mathrm{HAB}$ prediction. Research efforts funded by agencies such as California Sea Grant and the NOAA competitive HAB programs have resulted in advances in understanding and monitoring $\mathrm{HABs}$ in California and elsewhere, but outcomes were necessarily focused on specific regions, organisms, and impacts. California HAB researchers, stakeholders, and monitoring programs identified a needed statewide capacity that encompasses existing and emerging $\mathrm{HAB}$ issues and more effectively leverages new technologies in a coordinated manner. This led to development of the California Harmful Algal Bloom Monitoring and Alert Program (Cal-HABMAP) with an ambitious set of goals, including studies to normalize the diverse methodologies used in $\mathrm{HAB}$ research and monitoring, development of an economic analysis of resources along the California coast and the potential impact of HABs on these resources, and design and development of an integrated network of observations and models that are accessible to all HAB stakeholders.

FIGURE 1. Probability of cellular domoic acid (DA) exceeding 10 picograms per cell (left) and the overlap of that probability exceeding $60 \%$ with regions of high probability of bycatch (from the EcoCAST model), shown in purple (right) for May 5, 2020. Purple indicates areas with multiple risks for fishing. The merging of C-HARM and EcoCAST is an example of valueadded projects that support the California Marine Protected Area networks. On the right panel, several shore stations hosting Imaging FlowCytobots are indicated by black dots along with two mooring deployments marked by green dots.
Cal-HABMAP began as a grass-roots network of observing sites in 2008 with eight shore stations spanning southern to central California. While predating the establishment of the US Integrated Ocean Observing System (IOOS), it was quickly adopted by, and integrated with, the Central and Northern California Ocean Observing System (CeNCOOS) and the Southern California Coastal Ocean Observing System (SCCOOS) to provide robust Californiawide observations. Integration into the IOOS network ensured long-term stability of both funding and products and an opportunity to leverage ongoing efforts to facilitate research-to-operations as new technologies matured and were widely adopted by the community.

Today, Cal-HABMAP has greatly expanded in research scope and geographic range, achieving the vision set forth more than a decade ago (Kudela et al., 2015). In addition to the eight original sites, shore stations have been added at Bodega Marine Lab and Humboldt Bay. Northern California has emerged as a new HAB "hotspot" for domoic acid driven by climate change and the northward expansion of Pseudo-nitzschia, which led to the massive disruption of West Coast ecosystems, fisheries, and economies during the 2014-2015 marine heatwave; the Cal-HABMAP network effectively documented the impact and recovery of this event.

A limitation of Cal-HABMAP has been the lack of coverage along the coast and offshore, where sensing and sampling had historically occurred at only a small number of shore stations. The development of the California Harmful Algae Risk Mapping (C-HARM) system (Anderson et al., 2019) has largely addressed this limitation for the most common HAB events driven by the toxic diatom Pseudo-nitzschia. C-HARM generates and validates routine

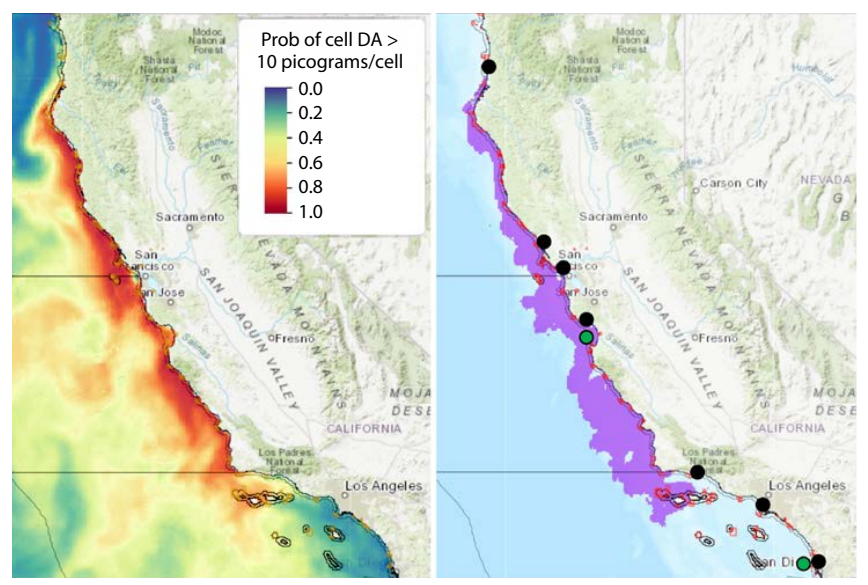


FIGURE 2. An Imaging FlowCytobot was recently deployed on a wave-powered buoy (bottom left). Photo credit: MBARI It processes $5 \mathrm{~mL}$ of seawater every 30 minutes, producing high-resolution images of each particle (top). The last three plankton images show the harmful algal bloom (HAB) organisms Alexandrium, Dinophysis, and Pseudonitzschia. The data are processed using machine learning to identify major groups (bottom right), providing an index of the entire plankton assemblage as well as target $\mathrm{HAB}$ species, in this case for June 2020 from Santa Cruz Wharf, California.

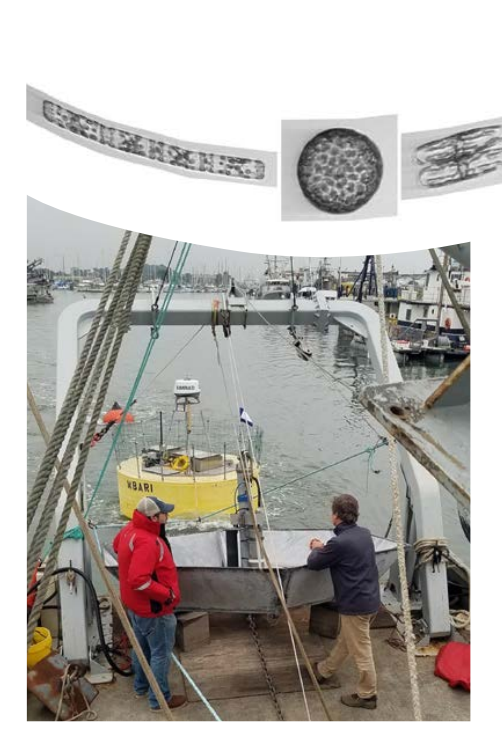

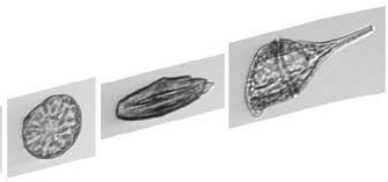
$-$

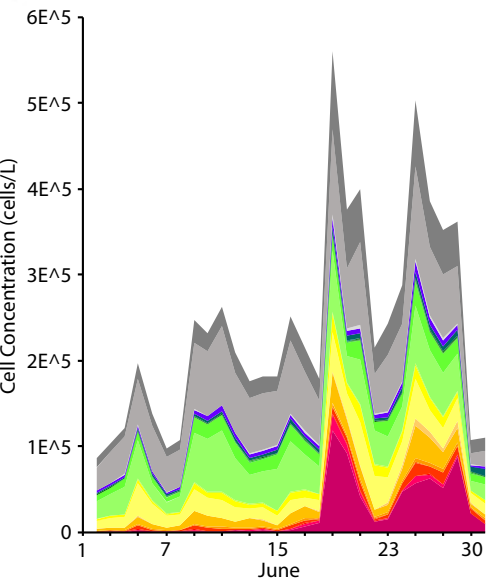

- Unclassified Nanoplankton $<10 \mu \mathrm{m}$ Dictyocha - Dictyocha - Thalassionema - Skeletonema - Pseudo-nitzschia - "Pennate" - Guinardia/Dactyliosolen - Eucampia Detonula/Ceratulina/.Lauderia - Cylindrotheca/Nitzschia

- Chaetoceros

"Centric"

Asterionellopsis

Scrippsiella/Heterocapsa Prorocentrum Lingulodinium Gymnodinium/Peridinium - Dinophysis - Margalefidinium - Ceratium Amylax/Gonyaulax/Protoceratium - Alexandrium - Akashiwo nowcast and forecast products for both Pseudo-nitzschia blooms and domoic acid. Statistical ecological models rely on an understanding of the underlying mechanics of bloom formation and utilize near-real-time information from numerical model simulations, satellite imagery, and field observations from both Cal-HABMAP and marine mammal stranding programs (Anderson et al., 2019). These maps are intended to be easily interpreted by end users; for example, a quote from the public portal notes that "as Dungeness crab fishermen, we are following these models daily." C-HARM predictions are also combined with other IOOS data to provide value-added products such as interactive data displays where stakeholders can identify overlapping areas of risk (Figure 1).

An exciting new network of IFCBs is being brought online to complement shore station and model observations with high temporal resolution ( $\sim 30$ minutes) plankton imagery. These instruments provide automated monitoring and classification of phytoplankton imagery at critical sites where many environmental observations are currently collected. The IFCB takes high-resolution images of fluorescing particles, primarily phytoplankton, and computer vision techniques provide standard morphometric data for each image, such as cell size and aspect ratio. Machine learning algorithms are then used to categorize images of taxonomic groups of interest, for example, Pseudo-nitzschia, while also providing information about the full community assemblage (Figure 2). Capturing the full assemblage is critical for understanding and predicting $\mathrm{HAB}$ events since $\mathrm{HABs}$ are just one component of the plankton. California leads the nation and world in creating the first such network of its size and paves the way for a National HAB Observing Network.

Cal-HABMAP's success emerges from several core principles. First, sustained funding and a pathway from research-to-operations has allowed the HAB community to capitalize on the rich historical research and monitoring programs in California. Second, Cal-HABMAP is compliant with standardization of essential ocean variables (Muller-Karger et al., 2018), and its goals are well aligned with the needs and goals of local, state, and federal agencies. Finally, Cal-HABMAP is responsive to the needs and requirements of end users. As noted by one stakeholder, Frances Gulland, Commissioner at the US Marine Mammal Commission and former Senior Scientist at the Pacific Marine Mammal Center, "There have been repeated calls for such capability at workshops and in publications from oceanographers, veterinarians, ecologists, and public health officials, as these blooms have dramatic effects on marine mammal health as well as on the economy and human health." We are hopeful that Cal-HABMAP can provide a successful example of how best to implement similar networks regionally, nationally, and internationally.

\section{REFERENCES}

Anderson, C.R., E. Berdalet, R.M. Kudela, C.K. Cusack, J. Silke, E. O'Rourke, D. Dugan, M. McCammon, J.A. Newton, S.K. Moore, and K. Paige. 2019. Scaling up from regional case studies to a global harmful algal bloom observing system. Frontiers in Marine Science 6:250, https://doi.org/ 10.3389/fmars.2019.00250.

Kudela, R.M., A. Bickel, M.L. Carter, M.D.A. Howard, and L. Rosenfeld. 2015. The monitoring of harmful algal blooms through ocean observing: The development of the California Harmful Algal Bloom Monitoring and Alert Program. Pp. 58-75 in Coastal Ocean Observing Systems. Y. Liu, H. Kerkering, and R.H. Weisberg, eds, Elsevier.

Muller-Karger, F.E., P. Miloslavich, N.J. Bax, S. Simmons, M.J. Costello, I. Sousa Pinto, G. Canonico, W. Turner, M. Gill, E. Montes, and others. 2018. Advancing marine biological observations and data requirements of the complementary Essential Ocean Variables (EOVs) and Essential Biodiversity Variables (EBVs) frameworks. Frontiers in Marine Science 5:211, https://doi.org/10.3389/fmars.2018.00211.

\section{ACKNOWLEDGMENTS}

Cal-HABMAP represents multiple organizations and partners who contribute to the operation and maintenance of the network. Core funding has been provided by NOAA, including the IOOS, ECOHAB, and MERHAB programs; NASA; California Sea Grant; California Ocean Protection Council; and numerous in-kind contributions from our partners and stakeholders. 


\section{AUTHORS}

Raphael M. Kudela (kudela@ucsc.edu), Ocean Sciences Department and Institute of Marine Sciences, University of California Santa Cruz, USA. Clarissa Anderson, Southern California Coastal Ocean Observing System, Scripps Institution of Oceanography, University of California San Diego, USA. Henry Ruhl, Central and Northern California Ocean Observing System, Monterey Bay Aquarium Research Institute, USA.

\section{ARTICLE CITATION}

Kudela, R.M., C. Anderson, and H. Ruhl. 2021. The California Harmful Algal Bloom Monitoring and Alert Program: A success story for coordinated ocean observing. Pp. 84-85 in Frontiers in Ocean Observing: Documenting Ecosystems, Understanding Environmental Changes, Forecasting Hazards. E.S. Kappel, S.K. Juniper, S. Seeyave,

E. Smith, and M. Visbeck, eds, A Supplement to Oceanography 34(4), https://doi.org/ 10.5670/oceanog.2021.supplement.02-30.

\section{COPYRIGHT \& USAGE}

This is an open access article made available under the terms of the Creative Commons Attribution 4.0 International License (https://creativecommons.org/ licenses/by/4.0/), which permits use, sharing, adaptation, distribution, and reproduction in any medium or format as long as users cite the materials appropriately, provide a link to the Creative Commons license, and indicate the changes that were made to the original content. 